\title{
Supercritical Fluid Chromatography-Mass Spectrometry (SFC-MS) and MALDI-TOF-MS of Heterocyclic Compounds with Trivalent and Pentavalent Nitrogen in Cough Relief Medical Forms Tuxi and Cosylan
}

\author{
Ilia Brondz ${ }^{1,2 *}$, Anton Brondz ${ }^{3}$ \\ ${ }^{1}$ Department of Biology, University of Oslo, Oslo, Norway \\ ${ }^{2} \mathrm{R} \&$ D Department, Jupiter Ltd., Ski, Norway \\ ${ }^{3}$ Department of Chemistry, Norwegian University of Science and Technology, Trondheim, Norway \\ Email: *ilia.brondz@bio.uio.no, *ilia.brondz@gmail.com, brondz@stud.ntnu.no
}

Received September 19, 2012; revised October 15, 2012; accepted October 31, 2012

\begin{abstract}
Alkaloids are natural, semisynthetic or synthetic organic compounds, normally polar with basic chemical properties and containing at least one nitrogen atom in a heterocyclic ring. Some synthetic or semisynthetic substances resemble the alkaloid architecture. Trivalent nitrogen in these substances is normal; however, some natural and semisynthetic alkaloids have pentavalent nitrogen. The drug pholcodine is a derivative of morphine. Pholcodine has very little addictiondeveloping effect. It is a semisynthetic alkaloid that was first synthesized in 1950 by Chabrier et al. Pholcodine possesses antitussive (cough relief) properties similar to codeine, morphine and ethylmorphine. The drug was used in liquid formulations as Tuxi and Tuxi Forte, and it is in present use in Tuxidrin as liquid mixture and in tablet form. Pholcodine is an Active Pharmacological Ingredient (API) in tablets and liquid mixtures. Leiras International and Weifa in Norway manufacture medical forms with pholcodine. Several impurities in pholcodine were described by J. Røe in 1997 and by Denk et al. in 2000 and 2002. In addition, several degradation products may be formed in liquid formulations under storage. Some of these products are related not to the original production of pholcodine but rather to its oxidation under storage. The appearance of degradation products strongly depends on the storage temperature and $\mathrm{pH}$ of the liquid phase. Pholcodine-N-oxide and pholcodine-N,N'-dioxide are among the degradation (oxidation) products; pholcodine can also degrade to morphine. There is little information about the toxicity of the N-oxide and no information on the N,N'-dioxide of pholcodine. In this study, the fact that morphine is generated during the storage of formulations containing pholcodine is presented. Another antitussive mixture under the name Cosylan was analyzed to examine the oxidation of ethylmorphine to ethylmorphine-N-oxide. Ethylmorphine is the API in Cosylan.
\end{abstract}

Keywords: SFC; Trivalent Nitrogen; Pentavalent Nitrogen; Pholcodine-N-oxide; Pholcodine-N,N’-dioxide; Morphine; Cosylan; Tuxi; Tuxi Forte; Tuxidrin

\section{Introduction}

Since September 2011, Leiras has been a part of Takeda, a global, research-based pharmaceutical company. Takeda is the $12^{\text {th }}$ largest company in the world. Weifa is a Norwegian private company, and one of the largest private pharmaceutical companies in Norway. Both companies manufacture antitussive (cough relief) medical forms. Pholcodine was accepted as a low-addiction substance, and thus Tuxi (a pholcodine-containing liquid mixture) did not need a prescription. However, use of pholcodine came under scrutiny in the past 10 years, and Weifa recalled the Tuxi liquid mixture from the market, although

"Corresponding author.
Tuxidrin (a pholcodine-containing liquid mixture) remained on the market.

In 1988, Findlay [1] stated in a review concerning the pholcodine: "The drug, which has been formulated in many combination medications (45)—some rational and some quite irrational pharmacologically—also appears to be active in man, although the clear-cut demonstrations, unfortunately, are in artificially-induced cough models", and "Pholcodine appears to be devoid of addiction liability in man. In contrast to codeine, pholcodine is not metabolized to morphine in man, a fact that may contribute to its more favorable toxicity profile, and it is metabolized and eliminated much more slowly than codeine".

Indeed, study of the transformation of the toxin or the 
drug should be conducted not only by analyzing its presence in blood, urine or the target organ, but also, for a start, by studying its transformations in the stomach, as was shown by Brondz et al. [2-4].

The close examination of the deterioration dynamics under storage shows the appearance of numerous degradation products including morphine, pholcodine-N-oxide (Figure 1) and other unknown substances.

Even at $\mathrm{pH} 4.0$, a significant percentage of pholcodine degrades to morphine. The $\mathrm{pH}$ in the stomach is about 1.0. The transformation of pholcodine at that $\mathrm{pH}$ has not been studied either in vivo or in vitro.

The recall of the Tuxi liquid mixture by Weifa from the market, while Tuxidrin remains on sale, is difficult to understand. All side effects for both formulations should be the same. Internal knowledge about the generation of morphine in Tuxi under storage has been available to Weifa for years [5].

The stability of Tuxi and Cosylan to degradation of the APIs (pholcodine and ethylmorphine respectively at room temperature) was evaluated by SFC and SFC-MS in this study.

The antitussive (cough relief) drugs are very important, and pholcodine is one of them. Cough is a well-known symptom of a variety of diseases, ranging from the common cold to tuberculosis and plague. Dust and pollen, smoke and chemical fumes, and aerosols of pesticides (especially those containing phosphororganic compounds, which inhibit the enzyme acetylcholinesterase (AChE)) are responsible for coughs in daily life. Young children are particularly vulnerable to the common cold and childhood infectious diseases. They often suffer from longlasting intense cough, including whooping cough. Intense coughing is not merely a symptom; it can be a disease in itself. Intense coughing may also cause a disturbance in the oxygen supply to tissues. In this respect, the brain is the most vulnerable organ.

Because of the presence of coregents and masking substances, the use of direct injection analyses of Tuxi and Cosylan by gas chromatography (GC) and GC-MS was not possible. The possible presence in the mixtures of thermo labile degradation products also prevented the choice of GC and GC-MS as analytical methods. SFC and SFC-MS were chosen as the tools for these direct injection analyses. There are several publications on the degradation of pholcodine to pholcodine-N-oxide and pholcodine-N,N'-dioxide [5-8].

\section{Materials and Methods}

\subsection{Instrumentation and Conditions}

SFC-MS analyses were performed on MiniGram SFC (Berger Instruments Inc., USA) running SFC-ProNTo software (Berger Instruments Inc., USA) and equipped with a K-2501 UV detector (Advanced Scientific Instruments Dr. Ing. Herbert Knauer GmbH, Berlin, Germany) set at a wavelength of $280 \mathrm{~nm}$. The MiniGram SFC was equipped with a Discovery ${ }^{\circledR}$ HS F5 HPLC column (25 $\mathrm{cm}$ long with a $4.6 \mathrm{~mm}$ I.D. and $5 \mu \mathrm{m}$ particle size; 567517-U) from Supelco (Supelco, Bellefonte, PA, USA).

A part of the flow stream was diverted by a 10/1 fixed splitter (UV/MS) and used to feed a Micromass PLCZ 4190 mass spectrometer (MS) equipped with ESI running MassLynx 4.0 software (Waters-Micromass, Manchester, UK). The connecting line to the MS was through T-form tubing equipped with a manually operated micro-valve and capillary restrictor, as described previously $[9,10]$. The MS conditions were a cone voltage of $60 \mathrm{~V}$, extractor voltage of $12 \mathrm{~V}$, capillary voltage of $4.5 \mathrm{kV}$, ion energy of $1.0 \mathrm{~V}$, multiplier at $400 \mathrm{~V}$, analyzer vacuum of $2.6 \mathrm{kPa}$ and a desolvation gas flow of $495 \mathrm{~L} \cdot \mathrm{h}^{-1}$. The mass-to-charge ratio was scanned automatically in the range from 60 to 600 . The MS was operated in the positive charge mode. The instrument was previously calibrated with sodium iodide.

Isocratic chromatography was performed using $\mathrm{CO}_{2}$ in the supercritical state with $30 \% \mathrm{EtOH} / 0.4 \%$ diethylamine organic modifier. The flow rate was $3 \mathrm{~mL}$. At the end of the analysis, the manually operated micro-valve was closed, thus closing the flow of eluate to the MS, and the tubing directing the eluate to the waste flow restrictor was then opened. The percentage of modifier in the eluate was increased to $50 \%$ at a rate of $10 \%$ per min, held at $50 \%$ for $3 \mathrm{~min}$, and then dropped down to the level required for analysis at a rate of $10 \%$ per min, where it was held for 3 min to stabilize the column. The manually operated micro-valve was then reopened to direct eluate to the MS for 3 min before analysis.

\subsection{Materials and Standards}

Tuxi (hostedempende, slimløsende) mixture produced by Weifa purchased in 2007 from the Norwegian Medicinal Depot (NMD, Norway) was held at room temperature in a brown glass bottle (original bottle) until the time of analysis in 2011. Cosylan mixture produced by ParkeDavis (Parke-Davis Scandinavia AB, Solna, Sweden) was purchased in 2007 from NMD (Norway) and was held at room temperature in a brown glass bottle (original bottle) until the time of analysis in 2011.

Standards: Pholcodine, morphine, ethylmorphine, pholcodine-N-oxide, pholcodine-N,N'-dioxide, morphine-Noxide and ethylmorphine- $\mathrm{N}$-oxide were kindly donated to the head of the R \& D department, Jupiter Ltd., Ski, Norway, by Senior Engineer J. Røe, head of the Analytical Laboratory, Weifa, Oslo, Norway.

Reagents: Ethanol 96\% (EtOH) (Arcus, Oslo, Norway), diethylamine of proanalysis quality (Merck, Darmstadt, Germany), $\mathrm{CO}_{2}$ in balloons (Hydro, Oslo, Norway) were used. 


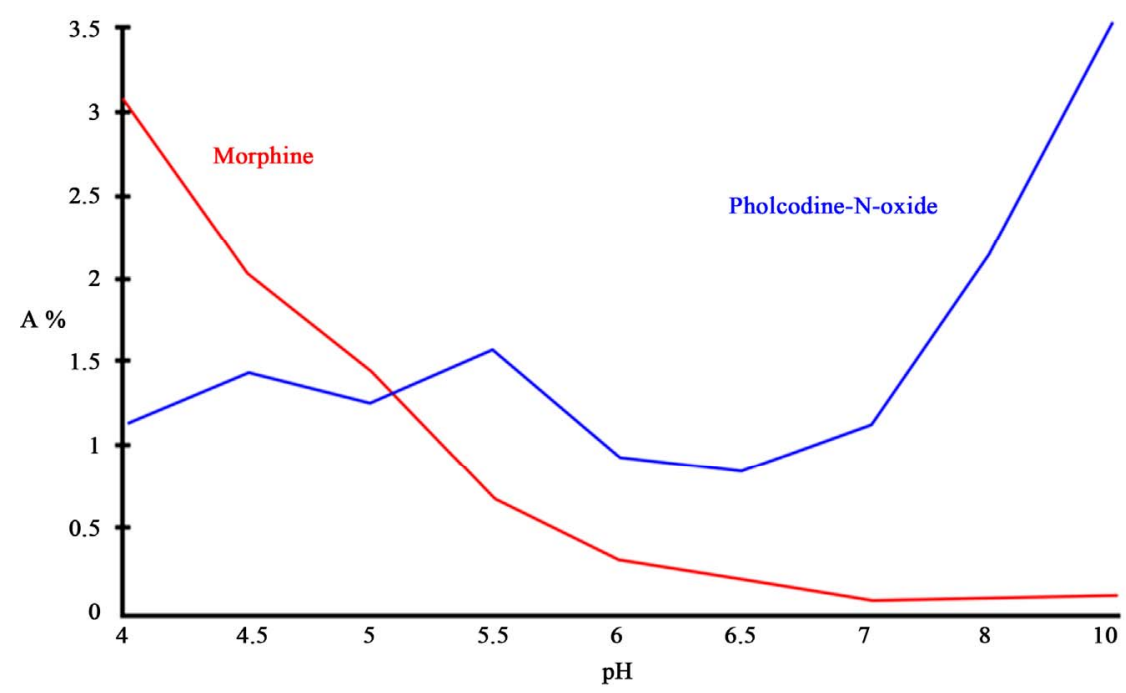

Figure 1. The \% presence of morphine is calculated as a \% of the total amount of pholcodine. The conditions were as follows. Solvent: doubly distilled water. Buffer: citric acid $0.25 \mathrm{M}$, pH adjusted with $\mathrm{NaOH}(20 \%)$ to the experimental level. Pholcodine hydrate $1 \%$ (concentration $0.024 \mathrm{M}$ ). Temperature: $60^{\circ} \mathrm{C}$. Duration of accelerated degradation was 63 days.

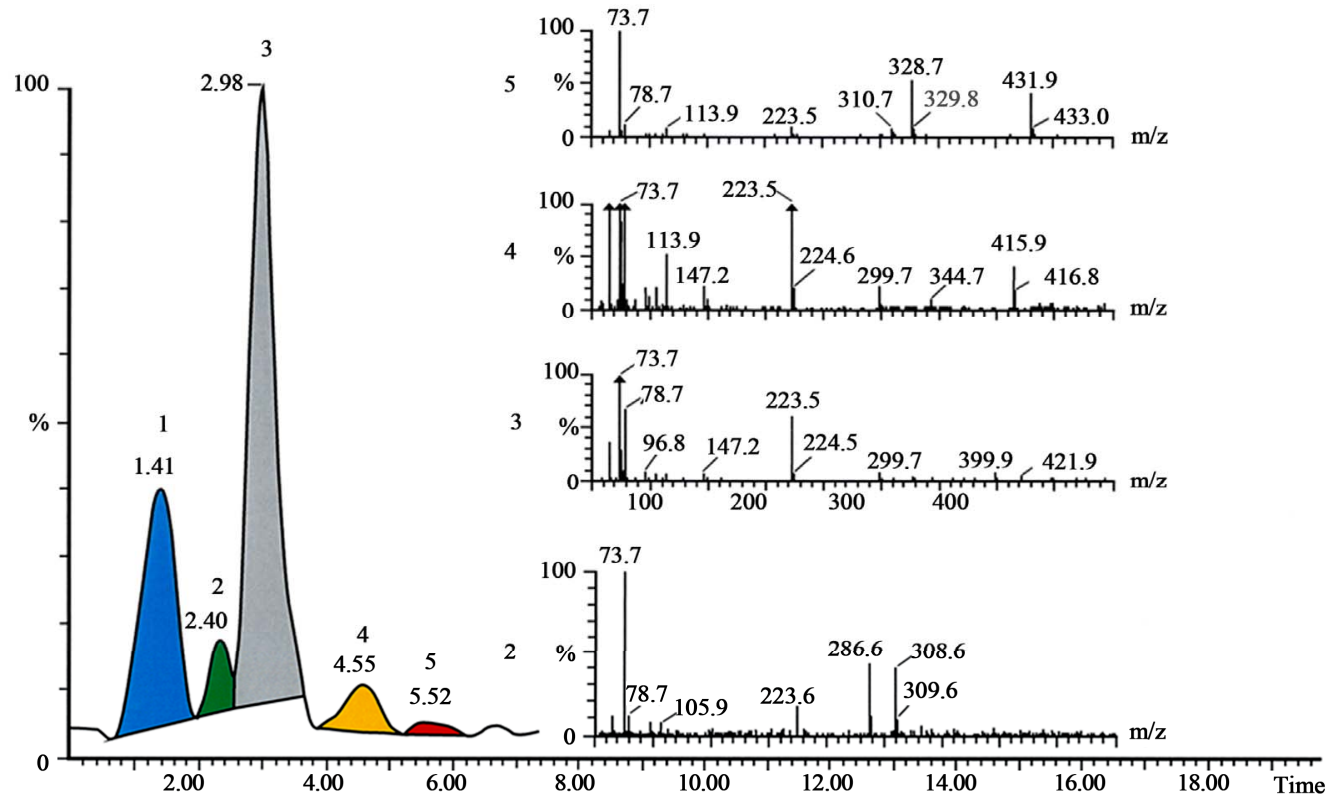

Figure 2. The SFC-MS analysis shows content of Tuxi. The conditions of analysis are described in the text. The peak 1 with $R_{t}$ 1.41 is unknown substance, the peak 2 with $R_{t} 2.40$ is morphine, the peak 3 with $R_{t} 2.98$ is pholcodine, the peak 4 with $R_{t} 4.55$ is pholcodine-N-oxide, and the peak 5 with $R_{t} 5.52$ is pholcodine-N,N'-dioxide. The mass spectra recorded under peaks shown on the figure.

\section{Results and Discussion}

Without any doubt, antitussive drugs represent an important class of drugs; the question is if some side effects of the opiates that are often used in such formulations are more harmful than the symptoms these drugs are treating. In Tuxi, it was possible to detect the presence of major API the pholcodine (peak 3), and the degradation products as morphine (peak 2), pholcodine-N-oxide (peak 4) and pholcodine-N,N'-dioxide (peak 5), shown in Figure 2. The retention times and mass spectra for morphine standards (Figure 3), pholcodine (Figure 4), pholcodine-N-oxide (Figure 5) and pholcodine-N,N'-oxide (Figure 6) were in agreement with the retention times and mass spectra in Figure 2. Additional experiments performed using MALDI-TOF mass spectrometry supported the results by demonstrating the presence of morphine and pholcodine-N-oxide in addition to the major 


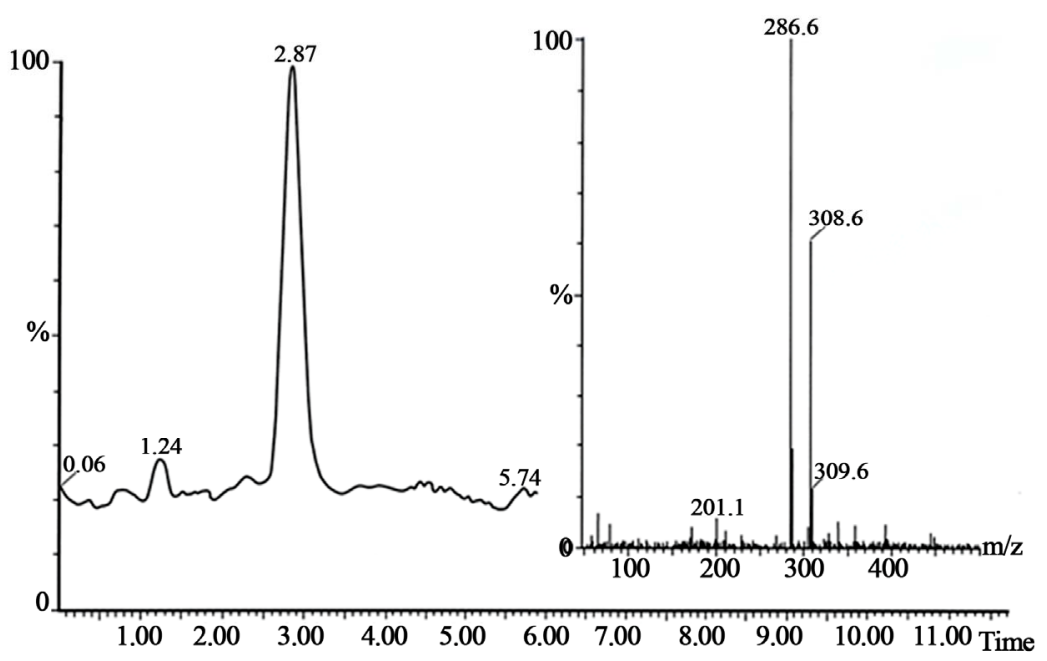

Figure 3. The peak with retention time 2.87 is the morphine standard and mass spectrum shown on the figure. The conditions for SFC-MS are in the text.

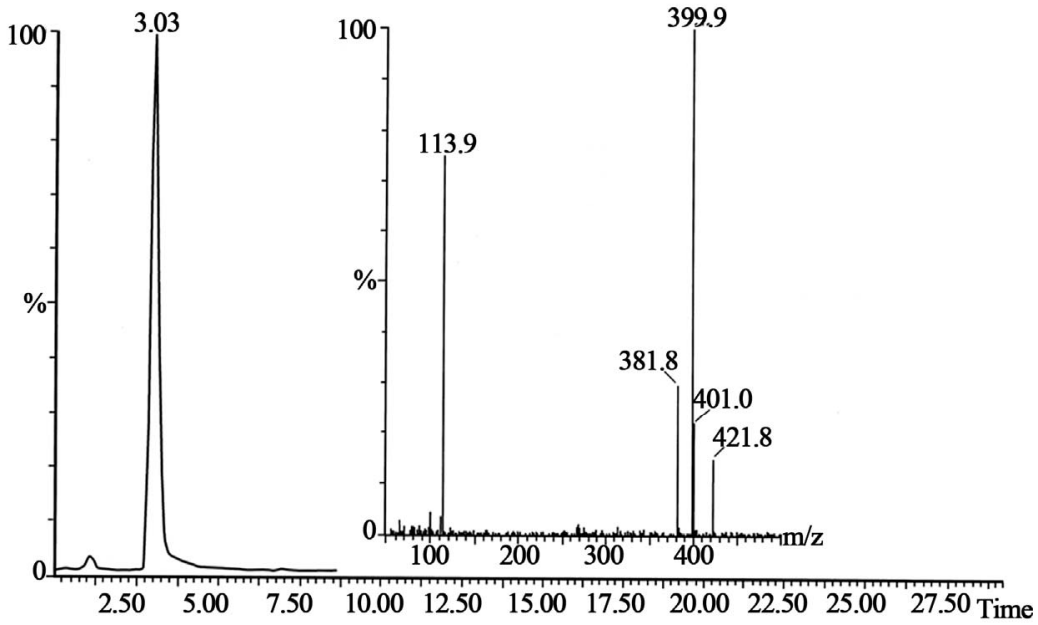

Figure 4. The peak with retention time 3.03 is the pholcodine standard and mass spectrum shown on the figure. The conditions for SFC-MS are in the text.

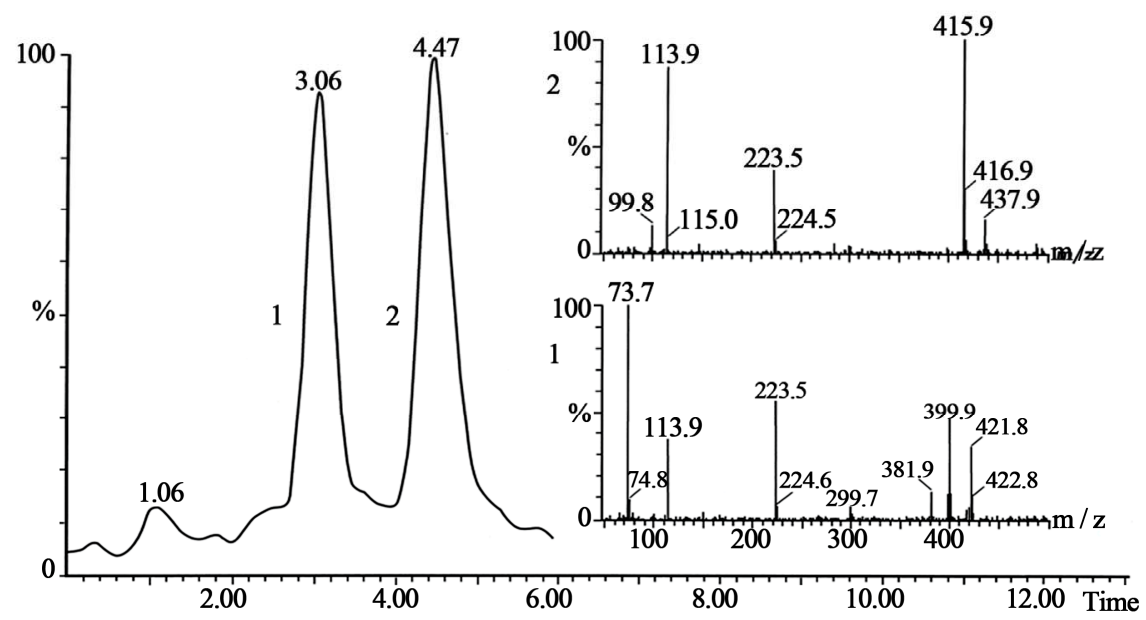

Figure 5. The peak 1 is the standard of pholcodine with retention time 3.06 and the peak 2 is the standard of pholcodine- $\mathrm{N}$-oxide with retention time 4.47, and mass spectra shown on the figure. The conditions for SFC-MS are in the text. 


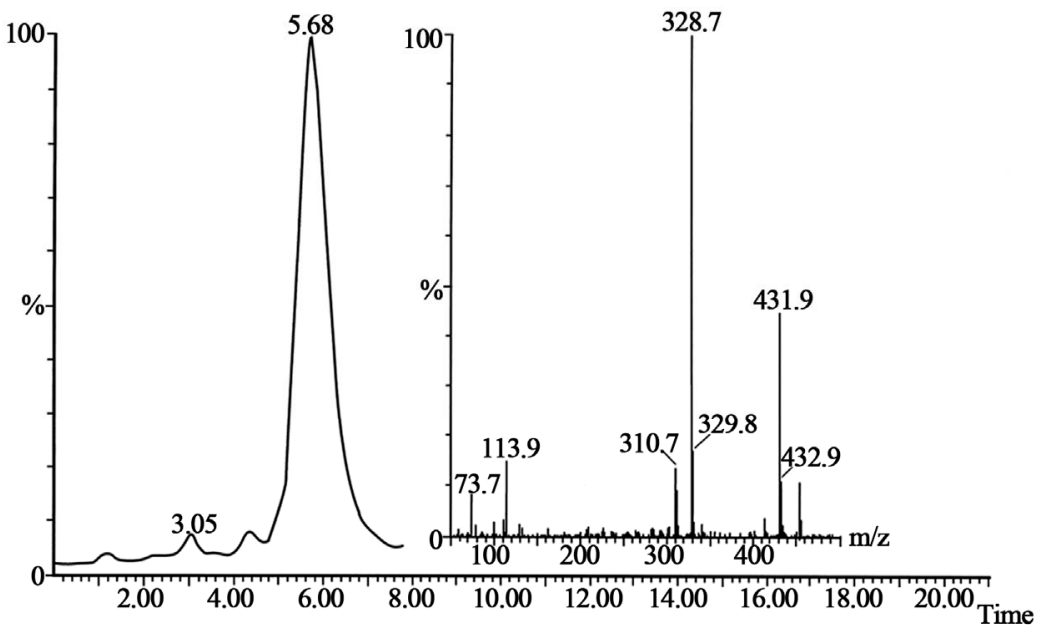

Figure 6. The peak with retention time 5.68 is the standard of pholcodine-N,N'-dioxide and mass spectrum shown on the figure. The conditions for SFC-MS are in the text.

compound pholcodine in Tuxi (Figure 7). The presence of pholcodine-N-oxides in Tuxi has been known since 1997 [5] and was later confirmed [6,7]. However, the presence of morphine in liquid formulations of pholcodine raises numerous questions. If pholcodine falls apart and one of the parts is morphine, what is the other part? Logically, the answer is ethylmorpholine or morpholine itself, but derivatives of these two also cannot be excluded. Discussion of the toxicity of ethylmorpholine or morpholine is beyond the scope of this paper; however, the presence of morphine is of interest. Morphine itself is an antitussive drug. The impact of the presence of morphine in the antitussive drugs Tuxi and Tuxidrin was not studied. Figure 1 presented the relation between $\mathrm{pH}$ and the percentage of morphine in pholcodine solution. A measurable transformation of pholcodine to morphine already takes place at $\mathrm{pH} 4.0$. In the stomach of humans, the $\mathrm{pH}$ is around 1.0. As has been shown [2-4], a significant transformation of substances can take place in the stomach during digestion. The stability of pholcodine at $\mathrm{pH} 1.0$ was not studied in these formulations. The fraction of pholcodine that is transformed in the stomach to morphine during digestion is not known. Addiction to pholcodine as a narcotic is very low; however, pholcodine degrades to morphine under storage and in the human stomach, and the question of the general development of an addiction to narcotics cannot be overlooked.

Additional experiments performed using MALDI-TOF mass spectrometry supported the results by demonstrating the presence of morphine and pholcodine-N-oxide in addition to the major compound pholcodine, in Tuxi.

The liquid mixture Cosylan manufactured by ParkeDavis (Parke-Davis Scandinavia AB, Solna, Sweden), which contains ethylmorphine as the API, was analyzed using SFC (Figure 8).

It was of interest to examine if it contained oxidation products such as morphine-N-oxide or ethylmorphine$\mathrm{N}$-oxide. The results of the analysis of ethylmorphine$\mathrm{N}$-oxide standard using SFC are shown in Figures 8 and 9 (chromatograms and mass spectra).

The peak in the chromatogram of Cosylan was found with a retention time corresponding to ethylmorphine standard peak 1 . No peaks that appeared in the chromatogram of Cosylan gave a mass spectrum resembling ethylmorphine-N-oxide standard peak 2 (Figure 9). Based on these facts it is possible to conclude that the Cosylan formulation was free of ethylmorphine-N-oxide.

Florvaag et al. demonstrated [11] in a pilot study that pholcodine stimulates a dramatic increase of IgE in IgEsensitized individuals. The quaternary amino function in pholcodine was implicated in the promotion of these reactions. However, the presence of a significant percentage of pholcodine- $\mathrm{N}$-oxides with pentavalent nitrogen amino functions was ignored.

As has been demonstrated, the broad spectrum of natural and oxidized opiates can be easily characterized by SFC-MS (it cannot be done by GC-MS without derivatization). This was possible even in very complex mixtures without any preliminary clean-up process by direct injection. All opiates, natural and semisynthetic, undergo oxidation to the corresponding $\mathrm{N}$-oxides. The percentage and nature of $\mathrm{N}$-oxides in the final product depend on the preparation process and time of storage. The N-oxides can serve as markers to reveal illegal laboratories preparing the drugs, purchasers and users. The $\mathrm{N}$-oxides and $\mathrm{N}, \mathrm{N}$ '-dioxides can also be used as markers in postmortem analyses in forensic medicine and in criminal investigations. Many other narcotics and alkaloids also undergo oxidation of trivalent nitrogen to pentavalent nitrogen.

$\mathrm{N}$-oxides and N,N'-dioxides of alkaloids can also be a pool of potential useful drugs. Morphine- $\mathrm{N}$-oxide is also 


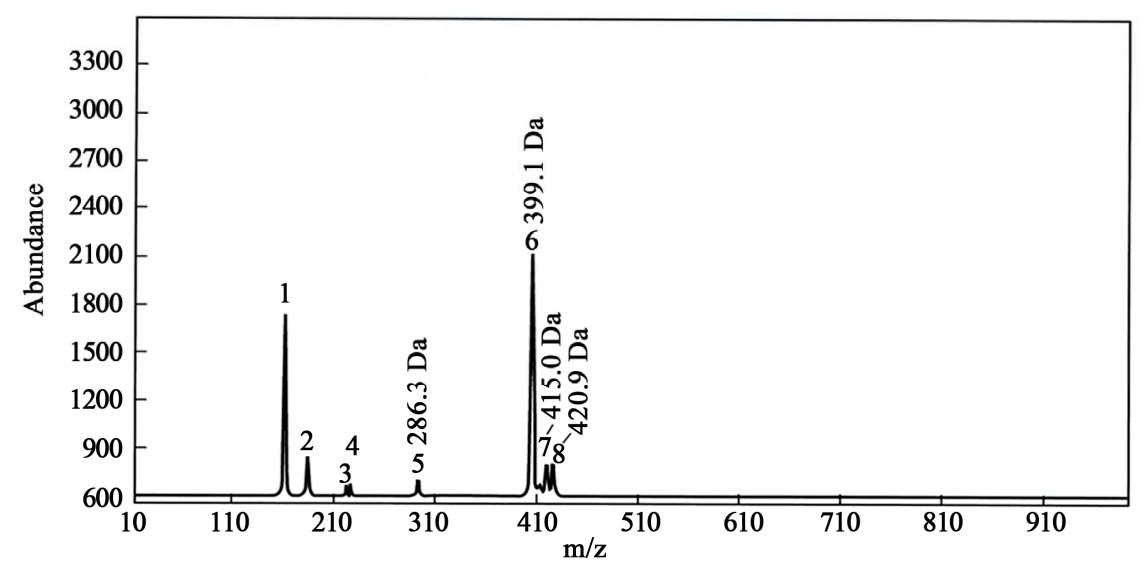

Figure 7. The presence of morphine in the Tuxi was supported by MALDI-TOF analysis, the morphine is peak 5, the pholcodine is peak 6 and the pholcodine- $\mathrm{N}$-oxide is peak 7.

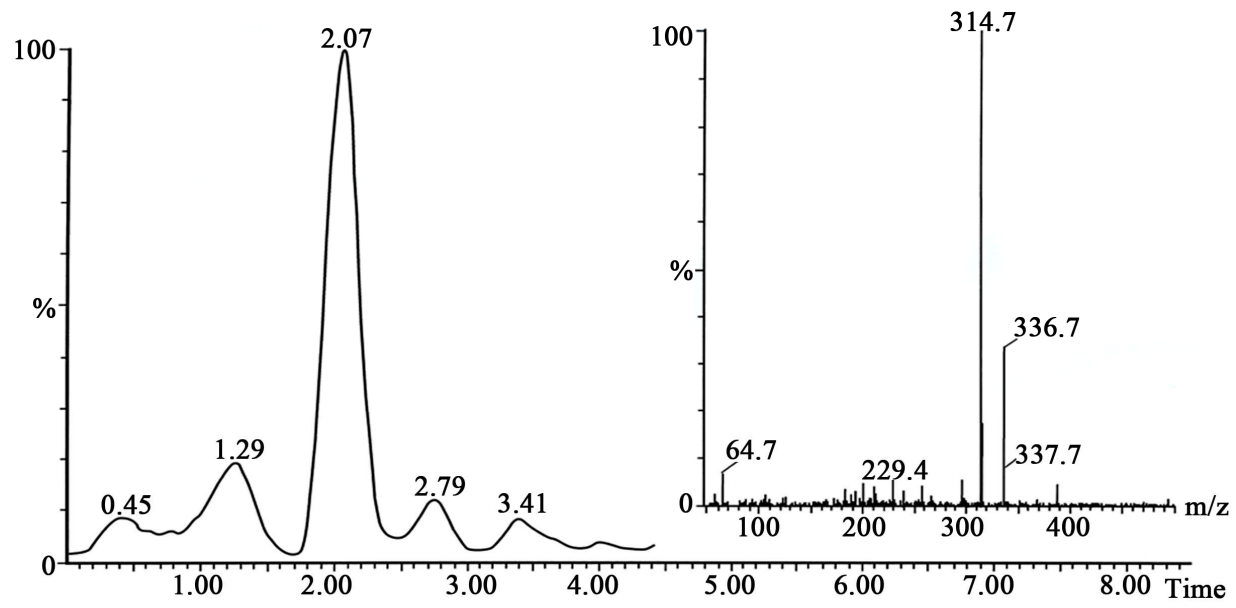

Figure 8. The SFC-MS analysis of the Cosylan liquid mixture shows that the major peak is ethylmorphine. No N-oxides of ethylmorphine or $\mathbf{N}, \mathbf{N}$ '-dioxides of ethylmorphine were found to be present in chromatogram.

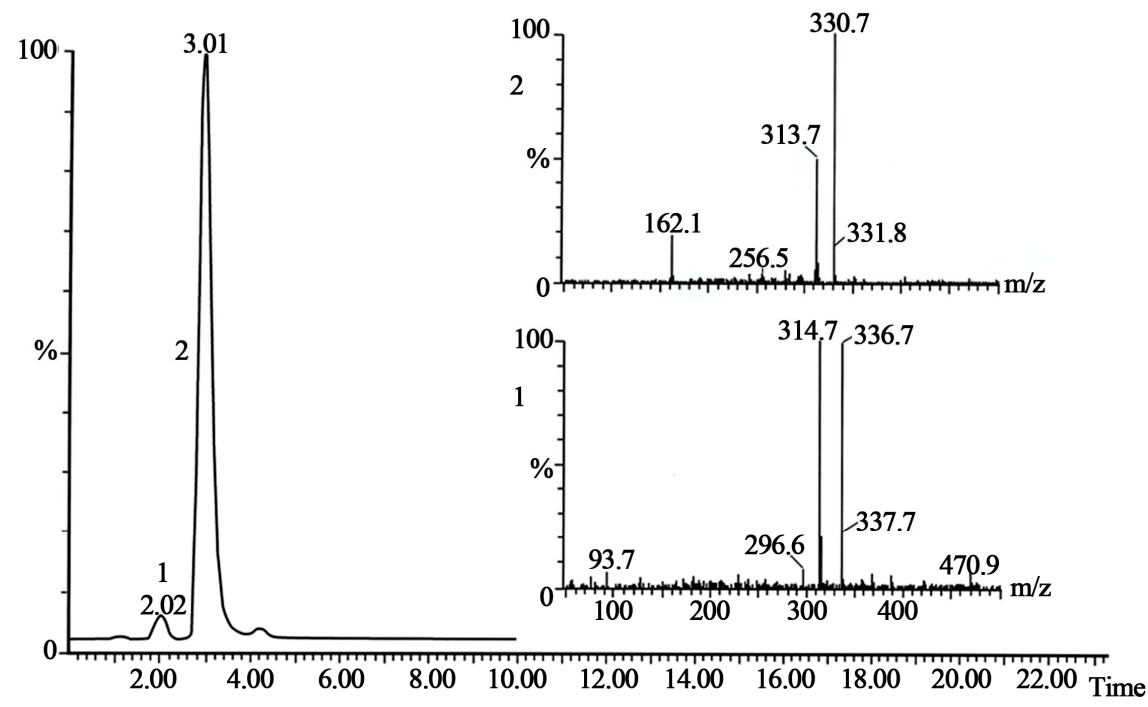

Figure 9. The peak with retention time 2.02 is the standard of ethylmorphine and the peak with retention time 3.03 is the standard of ethylmorphine-N-oxide. The mass spectra shown on the figure. 
an analgesic [12], while other N-oxides mimic the physiccological activities of the corresponding alkaloids (I. Brondz and J. Røe, to be published) [13].

\section{Conclusions}

1) The ability of SFC to analyze complex pharmaceutical formulations that contained a number of APIs and corregercia was demonstrated.

2) The presence of morphine as a degradation product of pholcodine was demonstrated in Tuxi under storage.

3) Cosylan was free of ethylmorphine-N-oxide after storage.

4) Morphine and other degradation products, such as pholcodine-N-oxide and pholcodine-N,N'-dioxide, were present in Tuxi.

5) It was a wise decision by Weifa to recall pholcodine - containing formulation Tuxi from the market; however, Tuxidrin is also a pholcodine-containing formulation.

\section{Acknowledgements}

The authors are grateful to engineer Jon Reierstad at the Technical Department, Photo and Graphic Laboratory, University of Oslo, Norway for technical support and to Jupiter Ltd., Norway for standards, and financial support.

\section{REFERENCES}

[1] J. W. Findlay, "Pholcodine," Clinical Pharmacology \& Therapeutics, Vol. 13, No. 1, 1988, pp. 5-17. doi:10.1111/j.1365-2710.1988.tb00502.x

[2] I. Brondz, E. Nevo, S. P. Wasser, K. Høiland, F. P. Størmer and A. C. Brondz, "Method Development for in vivo Analyses of Toxin Orellanine from the Toad Mushroom Cortinarius orellanus," Separation Science Europe 2011, London, 10-11 October 2011, p. 9.

[3] I. Brondz, E. Nevo, S. Wasser and A. Brondz, “A Direct Gas Chromatography-Mass Spectrometry (GC-MS) Method for the Detection of Orellanine Present in Stomach Content. Part I,” Journal of Biophysical Chemistry, Vol. 3, No. 1, 2012, pp. 29-34. doi:10.4236/jbpc.2012.31003

[4] I. Brondz and A. Brondz, “A High Performance Liquid
Chromatography-Mass Spectrometry (HPLC-MS) Qualitative Detection Method Developed for in vivo Analyses of Toxin Orellanine from the Cortinarius orellanus Fr. —Part II,” ISRN Chromatography, Vol. 2012, 2012, 5 p. doi: $10.5402 / 2012 / 293830$

[5] J. Røe, "Identification of Pholcodine Degradation Products/Determination of Chemical Structures," The 13th Technical Conference, Wilmington, 1997.

[6] O. M. Denk, A. I. Gray, G. G. Skellern and D. G. Watson, "Isolation and Identification of Three Potential Impurities of Pholcodine Bulk Drug Substance," Journal of Pharmacy Pharmacology, Vol. 52, No. 7, 2000, pp. 819-829. doi:10.1211/0022357001774679

[7] O. M. Denk, A. I. Gray, G. G. Skellern and D. G. Watson, "Impurity Profiling of Pholcodine by LC-ESI-MS," Journal of Pharmacy and Pharmacology, Vol. 54, No. 1, 2002, pp. 87-98. doi:10.1211/0022357021771788

[8] M. Jairaj, D. G. Watson, M. H. Grant, A. I. Gray and G. G. Skellern, "Comparative Biotransformation of Morphine, Codeine and Pholcodine in Rat Hepatocytes: Identification of a Novel Metabolite of Pholcodine," Xenobiotica, Vol. 32, No. 12, 2002, pp. 1093-1107. doi:10.1080/0049825021000017911

[9] I. Brondz, K. Høiland and J. Lefler, "Supercritical Fluid Chromatography of Secondary Metabolites and MultiAnalysis by Mass Spectrometry-Ultraviolet and Corona Charged Aerosol Detection," The 12th Norwegian MSWinter Meeting, Hafjell, 21-24 January 2007, p. 63.

[10] I. Brondz and K. Høiland, "Chemotaxonomic Differentiation between Cortinarius infractus and Cortinarius subtortus by Supercritical Fluid Chromatography Connected to a Multi-Detection System," Trends in Chromatography, Vol. 4, 2008, pp. 79-87.

[11] E. Florvaag, S. G. Johansson, H. Oman, T. Harboe and A. Nopp, "Pholcodine Stimulates a Dramatic Increase of IgE in IgE-Sensitized Individuals. A Pilot Study,” Allergy, Vol. 61, No. 1, 2006, pp. 49-55. doi:10.1111/j.1398-9995.2005.00933.x

[12] M. R. Fennessy "The Analgesic Action of Morphine-Noxide," British Journal of Pharmacology, Vol. 34, No. 2, 1968, pp. 337-344.

[13] I. Brondz and J. Røe, "Physiological Activities of NOxides and N, N'-Dioxides of Alkaloids,” in press. 